And how can it be that the very similar genomes of human beings and chimpanzees give rise to very different phonotypes when, in Drosophila, much larger differences of genotype specify flies that are very similar in form? Sheldrake's way of dealing with these and other observations is to borrow from embryology the vague notion of the morphogenetic field, the name given to the largely unidentified influences that give shape to a developing organism, and then to exalt this into a kind of universal agency. All aggregations of matter, animate or otherwise, are supposed to be exposed to a great variety of morphogenetic fields which fill the whole of space and which travel forwards in time. The effects of these morphogenetic fields (which are otherwise not described) are to ensure that particular aggregations of matter take on the form assumed by similar aggregations of matter elsewhere or at some earlier time. This is the "hypothesis of formative causation" - the subtitle of the book. The inheritance of acquired characteristics is at a stroke explained. Jung's collective unconscious is made inevitable. Instinctive animal behaviour becomes a non-problem, for there will be a morphogenetic field that ensures that each set of neurones in each central nervous system is put into an appropriate correspondence.

This argument would not be taken seriously were it not that others have done so. As things are, however, Sheldrake's book is a splendid illustration of the widespread public misconception of what science is about. In reality, Sheldrake's argument is in no sense a scientific argument but is an exercise in pseudo-science. Preposterously, he claims that his hypothesis can be tested - that it is falsifiable in Popper's sense - and indeed the text includes half a dozen proposals for experiments that might be carried out to verify that the forms of aggregations of matter are indeed moulded by the hypothetical morphogenetic fields that are supposed to pervade everything. These experiments have in common the attributes of being time-consuming, inconclusive in the sense that it will always be possible to postulate yet another morphogenetic field to account for some awkwardly inconclusive result and impractical in the sense that no self-respecting grantmaking agency will take the proposals seriously. This, however, is not the most serious objection to Sheldrake's attempt to endow his argument with an appearance of orthodoxy. The more serious objection to his argument is that it says nothing of any kind about the nature and origin of the crucial morphogenetic fields and contains no proposals for investigating the means by which they are propagated. Many readers will be left with the impression that Sheldrake has succeeded in finding a place for magic within scientific discussion - and this, indeed, may have been a part of the objective of writing such a book. But hypotheses can be dignified as theories only if all aspects of them can be tested. Sheldrake's hypothesis is no better than the hypothesis that a person equipped with a water-divining rod is able to detect subterranean water as a consequence of some intervening "field" generated by the presence of water, and his proposals for experimental tests no better than the argument that since waterdiviners succeed in making money, there must be something in the theory.

It is naturally distressing that these plain truths are not more widely understood. It is also a misfortune that the public expectation of what science can accomplish, now coloured by $\mathrm{Dr}$ Sheldrake's argument, should so conspicuously lack patience. Sheldrake's argument takes off from his catalogue of the ways in which the molecular biologists, no doubt the shock-troops of the reductionists, have so far been unable to calculate the phonotype of a single organism from a knowledge of its genotype. But so what? Have not the past twenty years shown clearly enough that molecular explanations of biological phenomena are, contrary to some earlier expectations, possible and powerful? And who says that molecular biology must be counted as a failure for as long as embryology is not a branch of mathematics? Dr Sheldrake, whose background should have enabled him to know better, has done a great disservice by helping to give currency to these misconceptions and false expectations. His book should not be burned (nor even confined to closed shelves in libraries) but, rather, put firmly in its place among the literature of intellectual aberrations.

\section{Back to gold standard?}

President Ronald Reagan's budgetary problems, not very different from those afflicting other governments in industrialized states, have nevertheless provoked a distinctively American and exceedingly curious response - the notion that present economic troubles might be made to go away by putting back the clock to 1971 and returning to the gold standard that was then abandoned. The proposal has surfaced on several occasions in the past few weeks, chiefly by means of hints or asides in the speeches of conservative economists and politicians. Last week, in a speech at Denver, Vice-President George Bush went so far as to say that this proposal should be seriously considered. He is clearly unaware that this stratagem for dealing with the economic problems of the United States is about as sensible as the proposal that fever should be treated by the immersion of the patient in iced water.

None of this implies that the problems of the United States economy can be allowed to solve themselves. On the contrary, it has become clear in the past few weeks that radical measures of some kind have become essential. The essence of the problem is that, at a time of rapid inflation, the Administration is planning to spend more than its revenue. Official estimates are that in the present financial year, the deficit will approach $\$ 50,000$ million, but both the Congressional Budget Office and the financial markets clearly believe that this estimate will be exceeded. So the Administration is hurriedly embarked on a process all too familiar in countries such as Britain - making last-minute adjustments to spending plans for the coming year and those that will follow. Mr Reagan now plans to reduce next year's spending by $\$ 17,000$ million, with larger cuts to follow in succeeding years, but the announcement of these plans has not steadied nerves in Wall Street nor brought interest rates (running at 20 per cent) down to the point at which industry will be encouraged to invest in the reinvigoration of the United States economy. The dilemma is depressingly familiar.

There is no doubt that a return to the gold standard would superficially be beneficial. Once it has been agreed that those who hold dollar bills may turn them into gold whenever they choose to do so, the capacity of governments to outspend their revenues is strictly limited by their capacity to find more gold to stockpile. Breaking the rules of sound money management becomes strictly impossible. But there is no reason why governments should put themselves in such a straitjacket simply with the objective of being forced by external circumstances to behave in a way they recognize to be desirable when they could achieve the same result by pure reason - by the exercise of self-restraint - and need not then have to squander resources on acquiring gold. Moreover, the disciplines of the gold standard can be needlessly cramping. Even monetarists agree that there may be circumstances, at the end of a long slump for instance, when governments would be wise to spend more than they raise in the form of taxes. To be tied in monetary policy to an artificial standard is not merely a confession of failure but potentially disastrous.

These are the reasons why Vice-President George Bush should not continue in public to speculate about the possibility that Fort Knox might be restocked with gold. If the Administration must have some crutch on which to lean in the months immediately ahead, it would be better advised to link the value of its currency to some quite different external standard, perhaps some shortlived exotic radioactive isotope whose permanent influence on the economy would be small. The trouble is that those holding dollars would be unwilling to trade their paper currency for such a material. In the circumstances, the Administration probably has no choice but to rely on the restraints that exist at present, the chief of which is the unwillingness of Congress to sanction the promised tax reduction, the planned increase of military expenditure and the reduction of welfare expenditure. That is why the present crisis in the United States economy has become a political as well as an economic embarrassment. With such obdurate critics, the Administration has no need of Fort Knox. 